\title{
Pengaruh Leverage Keuangan Terhadap Profitabilitas Pada Perusahaan Sub-Sektor Telekomunikasi Yang Terdaftar Di Bursa Efek Indonesia
}

\author{
Jogi Christian', Yayat Supriyatna' ${ }^{2}$ Umar Faruk ${ }^{3}$ \\ Program Studi Pendidikan Akuntansi, FPEB, Universitas Pendidikan Indonesia, Bandung, Indonesia ${ }^{1}$ \\ Program Studi Pendidikan Akuntansi, FPEB, Universitas Pendidikan Indonesia, Bandung, Indonesia ${ }^{2}$ \\ Program Studi Pendidikan Akuntansi, FPEB, Universitas Pendidikan Indonesia, Bandung, Indonesia ${ }^{3}$
}

\begin{abstract}
.
This study aims to describe the financial leverage and profitability of the company and how the influence of financial leveraege on profitability in the telecommunications sub-sector companies listed on the Indonesia Stock Exchange. With survey research through descriptive and verification methods, the research sample was 4 telecommunications companies in the period 2007-2016. The sampling technique uses Purposive Sampling, while the analysis technique uses simple linear regression using the help of EViews software 9. Based on the descriptive analysis of financial leverage from year to year it tends to be relatively up and fluctuating profitability but is quite decreased compared to the initial year of the study. The effect of financial leverage on profitability is $56 \%$ while the remaining $44 \%$ is influenced by other factors, the results of hypothesis testing indicate that the effect of financial leverage on profitability has a significant negative effect so that the results of the study can be generalized to the population.
\end{abstract}

Keywords. Financial Leverage; DAR; Profitability, ROA

\begin{abstract}
Abstrak
Penelitian ini bertujuan untuk mengetahui gambaran leverage keuangan dan profitabilitas perusahaan serta bagaimana pengaruh leveraege keuangan terhadap profitabilitas pada perusahaan sub-sektor telekomunikasi yang terdaftar di Bursa Efek Indonesia. Dengan penelitian survey melalui metode deskriptif dan verifikatif, sampel penelitian adalah 4 perusahaan telekomunikasi pada periode 2007-2016. Teknik sampling menggunakan Purposive Sampling, sedangkan teknik analisis menggunakan regresi linier sederhana menggunakan bantuan software EViews 9. Berdasarkan analisis deskriptif leverage keuangan dari tahun ke tahun cenderung relatif naik dan profitabilitas fluktuatif namun cukup menurun jika dibandingkan dengan tahun awal penelitian. Pengaruh leverage keuangan terhadap profitabilitas sebesar $56 \%$ sementara sisanya $44 \%$ dipengaruhi oleh faktor lain, hasil uji hipotesis menunjukkan bahwa pengaruh leverage keuangan terhadap profitabilitas berpengaruh negatif signifikan sehingga hasil penelitian dapat digeneralisasikan kepada populasi.
\end{abstract}

Kata Kunci. Leverage Keuangan, DAR, Profitabilitas, ROA

Corresponding author. Email. yayat_supriatna@upi.edu,umar_faruk@upi.edu

How to cite this article. Jogi, C., Yayat, S., \& Umar, F. (2018). Pengaruh Leverage Keuangan Terhadap Profitabilitas Pada Perusahaan Sub-Sektor Telekomunikasi Yang Terdaftar Di Bursa Efek Indonesia. Jurnal Pendidikan Akuntansi Dan Keuangan, 6(2), 9-104. Retrieved from http://ejournal.upi.edu/index.php/JPAK/article/view/15919

History of article. Received: Februari 2018, Revision: Mei 2018, Published: Juli 2018

\section{PENDAHULUAN}

Profitabilitas merupakan ukuran keseluruhan produktivitas dan kinerja perusahaan yang menunjukkan efisiensi dari produktivitas perusahaan dan efektivitas kinerja manajemen dalam mengelola kekayaan perusahaan. Analisis yang digunakan oleh perusahaan dalam mengukur profitabilitas yang dimilikinya antara lain Net Profit Margin (NPM), Gross Profit Margin (GPM), Return on Equity (ROE), Return on Assets (ROA). Diantara beberapa rasio profitabilitas, ROA merupakan indikator penting untuk mengukur kemampuan perusahaan dalam menghasilkan keuntungan dengan menggunakan aktiva yang dimiliki oleh perusahaan.

Menurut Brigham dan Houston (2013:109) "rata-rata nilai ROA perusahaan pada kondisi yang tidak sehat adalah kurang dari 9\%." Return on Assets memberikan gambaran yang lebih luas dibandingkan dengan metode lainnya karena menghitung aset secara keseluruhan. ROA dapat memberikan ukuran yang lebih baik atas profitabilitas suatu 
perusahaan karena dapat menunjukkan tingkat efektifitas manajemen dalam penggunaan aktiva dalam memperoleh laba. Data tingkat profitabilitas yang diukur menggunakan Return On Asset (ROA) pada perusahaan telekomunikasi yang terdaftar di Bursa Efek Indonesia pada periode 2011-2016 dapat dilihat dalam tabel berikut ini.

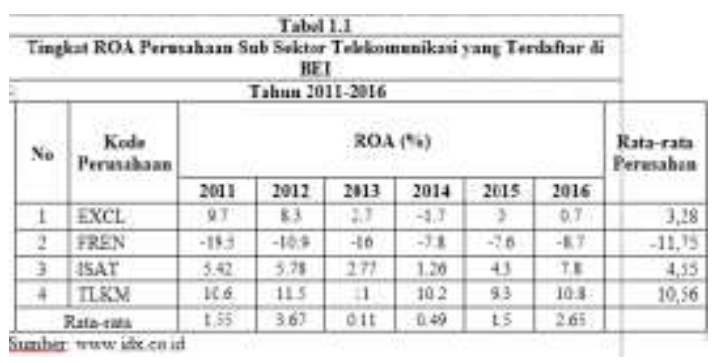

Tabel 1 menunjukkan bahwa sebagian besar perusahaan memiliki tingkat ROA yang dibawah standar industri sebesar 9\%. Dari keempat perusahaan tersebut, ROA tertinggi dicapai oleh PT. Telekomunikasi Indonesia Tbk (TLKM) pada tahun 2012, yang artinya total aktiva yang dimiliki perusahaan tersebut pada tahun 2012 mampu menghasilkan laba bersih sebesar $11,5 \%$. Sementara perusahaan yang memiliki ROA terkecil adalah PT. Smartfren Tbk (FREN) yaitu sebesar $-19,5 \%$ pada tahun 2011. ROA yang negatif menandakan bahwa perusahaan tersebut belum baik dalam pengelolaan aset perusahaan. Berdasarkan Tabel 1.1 dapat diketahui terdapat 7 dari 24 data atau setara $29,16 \%$ data yang telah memenuhi standar minimum ROA untuk perusahaan. Sementara sisanya sebanyak 17 data atau setara $70,84 \%$ masih berada dibawah standar minimum ROA perusahaan. Hal tersebut membuktikan bahwa profitabilitas perusahaan sektor telekomunikasi masih sangat rendah. Ini merupakan sebuah masalah dan harus segera diatasi.

Dengan mengetahui faktor-faktor tersebut maka perusahaan dapat mengambil suatu tindakan dalam menghadapi nilai profitabilitas ketika sedang mengalami penurunan. Hubungan profitabilitas dengan leverage ditunjukkan dengan pernyataan yang diberikan oleh Harjito (2014:315) "leverage dalam pengertian bisnis mengacu pada penggunaan asset dan sumber dana (sources of funds) oleh perusahaan di mana dalam penggunaan asset atau dana tersebut harus mengeluarkan biaya tetap atau beban tetap.
Dalam menjaga tingkat profitabilitas perusahaan agar tetap baik, pihak manajemen yang telah memilih untuk menggunakan leverage keuangan dalam struktur modal harus mampu mengelola dananya sebaik mungkin agar tujuan dari penggunaan leverage keuangan yaitu berupa peningkatan profitabilitas dapat tercapai. Namun apabila pihak manajemen tidak dapat mengelola dana yang berasal dari penggunaan leverage keuangan secara baik maka akan merugikan perusahaan. Penggunaan leverage keuangan yang berlebihan tidak akan baik bagi perusahaan karena biaya tetap berupa biaya pokok dan biaya bunga yang timbul akan mengurangi pendapatan perusahaan dan keuntungan yang diterima perusahaan akan berkurang sehingga berakibatkan pada menurunnya tingkat profitabilitas perusahaan, hal ini membuat perusahaan kurang mendapatkan kepercayaan dari para investor dalam masalah penanaman modal karena perusahaan dianggap tidak akan memberikan keuntungan. Jika penggunaan leverage keuangan berlebihan terus berlangsung akan berdampak terhadap profitabilitas yang menurun dan akan membuat kekurangan modal perusahaan dikarenakan investor yang kurang percaya sehingga memicu indikasi perusahaan mengalami kesulitan keuangan (financial distress) dan pada akhirnya mengakibatkan kebangkrutan.

Berdasarkan uraian di atas, maka secara visualisasi hubungan variabel untuk penelitian ini dapat digambarkan seperti gambar 2.1 sebagai berikut :

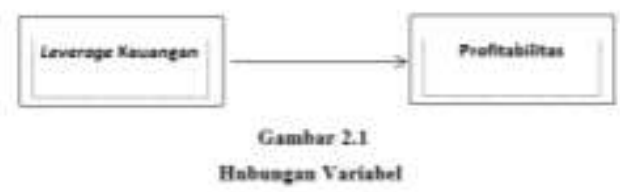

\section{METODE}

Metode deskriptif digunakan dalam penelitian ini untuk menggambarkan leverage keuangan dan profitabilitas pada perusahaan sub-sektor telekomunikasi yang terdaftar di Bursa Efek Indonesia, sementara metode verifikatif dalam penelitian ini digunakan untuk menguji ulang bagaimana pengaruh leverage keuangan terhadap profitabilitas pada perusahaan sub-sektor telekomunikasi yang terdaftar di Bursa Efek Indonesia. Penelitian ini terdiri dari dua variabel yaitu (1) Leverage Keuangan merupakan pemerolehan aktiva 
dengan dana yang diperoleh dari kreditur atau pemegang saham preferen dengan tingkat pengembalian tertentu. Pada perhitungannya leverage akan diukur oleh debt to assets ratio (DAR). (2) Profitabilitas merupakan kemampuan perusahaan untuk menghasilkan laba selama periode tertentu yang akan diukur menggunakan rasio return on assets (ROA).

Populasi yang digunakan dalam penelitian ini adalah seluruh perusahaan yaitu lima perusahaan sub sektor telekomunikasi yang terdaftar di Bursa Efek Indonesia (BEI).

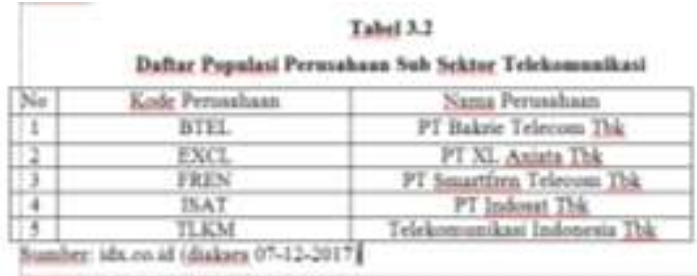

Dalam penelitian ini teknik sampling yang digunakan adalah Purposive Sampling. Perusahaan-perusahaan sub-sektor telekomunikasi yang terdaftar di Bursa Efek Indonesia periode 2007-2016. (1) Perusahaanperusahaan sub-sektor telekomunikasi yang menyajikan laporan keuangan secara berturutturut dari periode 2007-2016 di website Bursa Efek Indonesia. (2) Perusahaan memiliki data yang dibutuhkan untuk penelitian

Berdasarkan kriteria tersebut maka dapat diperoleh sampel sebanyak empat perusahaan dalam kurun waktu sepuluh tahun, sehingga terdapat 40 data observasi

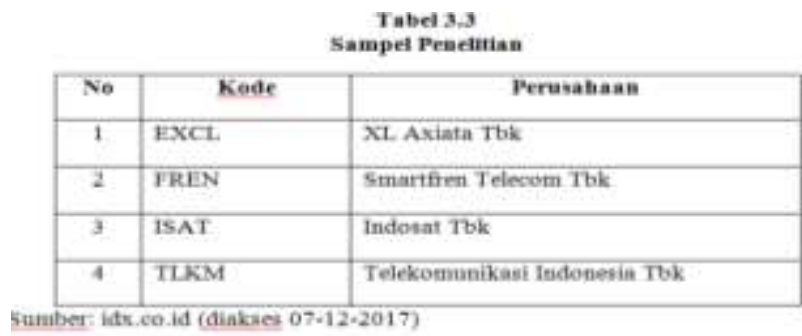

Variabel leverage keuangan dapat mempengaruhi profitabilitas karena leverage keuangan menggambarkan kemampuan perusahaan dalam menghasilkan laba dengan menggunakan modal sendiri atau modal dari luar (leverage). Leverage dalam penelitian ini menggunakan indikato debt to assets ratio (DAR), dimana semakin tinggi rasio DAR semakin rendah kemampuan perusahaan dalam menghasilkan laba, dikarenakan semakin tingginya investasi aktiva perusahaan dibiayai oleh utang.
Berdasarkan analisis deskiptif yang telah ditunjukkan pada tabel 4.1 dan gambar 4.1 mengenai gambaran leverage dengan indikator debt to assets ratio (DAR) dapat dilihat bahwa rata-rata DAR perusahaan sub-sektor telekomunikasi dari tahun 2007-2016 adalah $64,10 \%$, artinya menggambarkan bahwa dari setiap Rp. 1,00 yang tertanam pada total aktiva, perusahaan tidak mampu menutupi kewajiban perusahaan sebesar 64,10. Leverage keuangan pada perusahaan sub-sektor telekomunikasi dari tahun 2007-2016 cenderung fluktuatif naik. Nilai rata-rata DAR tertinggi perusahaan subsektor telekomunikasi pada tahun 2007 sampai 2016 ditempati oleh PT Smartfren Telecom Tbk (FREN) dengan DAR sebesar $102,66 \%$ pada tahun 2010. Hal ini menunjukkan selama tahun 2007 sampai 2016 bahwa manajemen perusahaan tersebut lebih menggunakan utang daripada total asset yang dimiliki perusahaan, sedangkan perusahaan dengan nilai rata-rata DAR terendah dari tahun 2007 sampai 2016 dimiliki oleh Telekomunikasi Indonesia Tbk (TLKM) dengan nilai rata-rata leverage sebesar $38,9 \%$ pada tahun 2014. Hal tersebut membuktikan bahwa manajemen perusahaan tersebut memperkecil pinjaman dari luar atau memperkecil pinjaman utang dan bisa mengelola total asset yang dimiliki perusahaan. Dengan tingginya tingkat leverage perusahaan menunjukkan bahwa total utang perusahaan lebih besar dibandingkan dengan total aktiva yang dimiliki perusahaan. Hal tersebut akan berdampak pada lebih besarnya beban (bunga) yang dikeluarkan oleh perusahaan karena beban yang muncul akibat dari adanya utang bertambah, akan menyebabkan perusahaan dalam menghasilkan laba menjadi rendah. Dengan demikian, tingkat leverage perusahaan sub-sektor telekomunikasi yang tinggi mencerminkan bahwa semakin banyak aktiva yang dibiayai oleh utang, akan mengurangi laba yang diterima oleh perusahaan dan akan meningkatkan resiko perusahaan sub-sektor telekomunikasi tidak bisa membayar utangnya pada pihak kreditor.

Dari hasil pengujian dengan menggunakan analisis regresi sederhana. Berdasarkan pengujian keberartian regresi melalui uji $F$ dari pengolahan data menggunakan EViews 9 bahwa nilai $F_{\text {hitung }}>$ $F_{\text {tabel, }}$ yaitu sebesar 47,20276> 4,10 dan nilai probabilitas (F-statistik) sebesar $0,0000 \leq 0,05$, maka $\mathrm{H}_{\mathrm{o}}$ ditolak dan $\mathrm{H}_{1}$ diterima atau dengan 
kata lain regresi berarti. Setelah regresi berarti dan bisa digunakan, selanjutnya dilakukan pengujian keberartian koefisien regresi dengan uji-t, dan dari hasil pengujian diperoleh kesimpulan bahwa hasil dari uji $t_{\text {hitung }}$ sebesar $6,799495 \leq-\mathrm{t}_{\text {tabel }}$ yang memiliki nilai sebesar 1,68595 maka maka $H_{0}$ ditolak dan $H_{1}$ diterima, dan nilai probabilitas (t-statistik) sebesar 0,0000 $\leq 0,05$. Hal tersebut menunjukkan leverage keuangan berpengaruh negatif signifikan terhadap profitabilitas. Artinya apabila leverage keuangan meningkat maka profitabilitas akan menurun, dan sebaliknya apabila leverage keuangan menurun maka profitabilitas akan meningkat, sehingga hasil penelitian tersebut dapat digeneralisasikan kepada populasi.

Adanya pengaruh negatif dapat diartikan bahwa semakin tinggi leverage dengan indikator debt to assets ratio (DAR) semakin besar risiko keuangannya. Peningkatan risiko yang dimaksud adalah kemungkinan terjadinya gagal bayar (default) karena perusahaan terlalu banyak melakukan pendanaan aktiva untuk kegiatan operasional dari utang. Dengan adanya risiko gagal bayar, maka biaya yang harus dikeluarkan oleh perusahaan untuk mengatasi masalah ini semakin besar. Hasil penelitian ini sesuai dengan teori trade-off bahwa penggunaan leverage keuangan mempunyai pengaruh negatif terhadap profitabilitas, teori trade-off menyatakan bahwa penggunaan utang yang banyak maka semakin besar bunga yang harus dibayar sehingga meningkatkan financial distress dan dapat mengurangi profitabilitas.

\section{SIMPULAN}

Berdasarkan dari hasil pembahasan dan penelitian yang telah dilakukan, dan dapat ditarik kesimpulan bahwa Gambaran leverage perusahaan sub-sektor telekomunikasi yang terdaftar di Bursa Efek Indonesia (BEI) dengan indikator Debt to Assets Ratio (DAR) menunjukkan fluktuasi yang cenderung naik dengan rata - rata nilai DAR sebesar $64 \%$. Dengan tingginya nilai DAR maka dapat disimpulkan bahwa perusahaan memiliki utang yang lebih besar dibandingkan dengan aktiva yang dimilikinya

Gambaran profitabilitas perusahaan subsektor telekomunikasi yang terdaftar di Bursa Efek Indonesia (BEI) dengan indikato Return on Assets (ROA) menunjukkan fluktuasi yang cenderung turun dengan rata-rata $1,81 \%$.
Leverage keuangan berpengaruh negatif terhadap profitabilitas pada perusahaan subsektor telekomunikasi yang terdaftar di Bursa Efek Indonesia.

Berdasarkan hasil penelitian yang dilakukan mengenai pengaruh leverage keuangan terhadap profitabilitas pada perusahaan sub-sektor telekomunikasi yang terdaftar di Bursa Efek Indonesia, maka penulis memberikan saran dan masukan yang diharapkan dapat memberikan manfaat dan bahan pertimbangan bagi pihak yang berkepentingan Untuk perusahaan-perusahaan dalam sub-sektor telekomunikasi dengan leverage yang tinggi, disarankan untuk lebih dipertimbangkan dalam menggunakan utang secara lebih efektif dan efisen dari besar kecilnya komposisi utang dalam menghasilkan profit bagi perusahaan. karena seperti dibahas sebelumnya bahwa akan selalu ada trade-off antara return dan risk bagi perusahaan, dimana penambahan utang selain membantu pendanaan bagi perusahaan akan tetapi juga disisi lain akan meningkatkan beban dan resiko dari perusahaan tersebut.

Bagi peneliti yang akan mengambil topik sejenis, disarankan untuk melakukan kajian lebih lanjut tentang variabel-variabel yang digunakan. Juga gunakan variasi rasio yang berbeda agar diketahui rasio mana yang lebih baik untuk digunakan dalam penelitian jenis ini. Juga disarankan untuk meneliti dari sektor lain dengan menggunakan sampel yang lebih besar agar diketahui perbedaannya.

\section{DAFTAR PUSTAKA}

Ambarwati, S. (2010). Manajemen Keuangan Lanjutan. Cetakan Pertama. Yogyakarta: Graha Ilmu

Brigham \& Houston. (2011). Dasar-dasar Manajemen. Keuangan, Edisi 11, Penerjemah Ali Akbar Yulianto, Salemba Empat,. Jakarta.

Kasmir. (2008). Analisis Laporan Keuangan. Edisi Pertama. Jakarta : PT. Raja Grafindo Persada.

Margaretha, Farah. 2011. Teori Dan Aplikasi Manajemen Keuangan Investasi dan Sumber Dana Jangka Pendek. Jakarta: Grasindo Gramedia Widiasarana Indonesia

Rohmana, Yana. (2010). Ekonometrika Teori dan Aplikasi dengan Eviews. Bandung: Laboratorium Pendidikan Ekonomi dan Koperasi Universitas Pendidikan Indonesia 
Abdul, A., Adelabu, I.T. (2015). Impact of Financial Leverage on Firm Performance: Evaluation of Total Nigeria PLC. International Journal of Science Commerce and Humanities, Volume No 3 No 6

Bursa Efek Indonesia Laporan Keuangan dan Laporan tahunan Perusahaan Sub Sektor Telekomunikasi.

Tersedia http://www.idx.co.id/ 